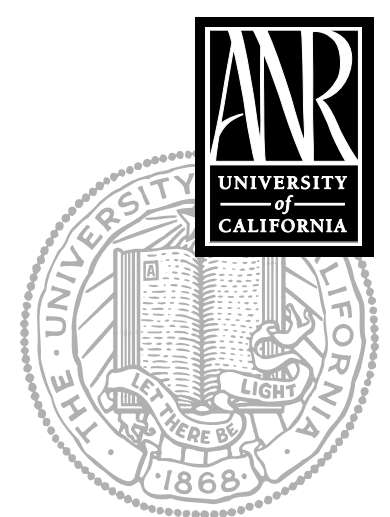

UNIVERSITY OF CALIFORNIA

Division of Agriculture and Natural Resources http://anrcatalog.ucdavis.edu

\section{CHRONIC WASTING DISEASE}

Chronic wasting disease (CWD) is a neurological disease of deer and elk first diagnosed in Colorado in 1967. CWD is a fatal disease to the whitetail deer, blacktail deer, mule deer, and elk that contract it. Scientists believe it is caused by a small protein called a prion. Prions concentrate where there is nerve tissue, such as the brain, spinal cord, eyes, and in the lymph nodes and spleen. Prions have not been found in meat (muscle tissue). According to the World Health Organization, there is no evidence that CWD passes to human beings. Nevertheless, hunters are advised to remove tissue where prions can be found.

A useful video about CWD for hunters, "Shedding Light on Chronic Wasting Disease" is available from the Chronic Wasting Disease Alliance Web site, http:// www.cwd-info.org. This video demonstrates recommended

(continued)

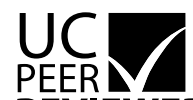

REVIEWED

\section{Protecting Food Safety When Shooting, Field Dressing, Bringing a Deer Home, and Cutting the Carcass}

CHRISTINE M. BRUHN, Cooperative Extension Specialist, University of California, Davis

Recent outbreaks of foodborne illness traced to venison, as well as the emergence of chronic wasting disease (CWD), have led to changes in recommended field dressing practices for deer. With proper care, deer can be safely dressed and venison can be safely enjoyed. Follow the recommended practices in this publication and consult your local California Department of Fish and Game (DFG) office for information on disease monitoring in your area.

\section{GENERAL GUIDELINES FOR FIELD DRESSING}

- Wear rubber or latex gloves.

- Minimize contact with the brain, spinal cord, spleen, and lymph nodes (lumps of tissue next to organs or in fat and membranes) as you work.

- Do not use household knives or utensils.

- Remove all internal organs.

- Clean residues from knives and equipment and disinfect them with a solution of 1 teaspoon of chlorine bleach in 1 quart of water $(5 \mathrm{ml}$ bleach in 1 liter of water). When cutting up the carcass at home, wipe down counters and let them dry; soak knives in the bleach-water solution for 1 hour. This will help kill harmful bacteria.

\section{SHOOTING THE DEER}

Tender, good-tasting venison begins with a quick, clean kill. Shoot only at a standing or slowly walking deer. Never shoot at a running deer.

- If you shoot at a running deer, it is very likely that you will only wound the animal and allow it to escape, causing it to suffer unnecessarily and perhaps die a day or more later.

- If you recover a wounded deer, there is a good chance the shot will have punctured the stomach, bowel, or bladder, contaminating the meat and producing undesirable flavors.

\section{Where to Aim}

Aim at a point midway between the top of the back and the bottom of the chest slightly behind the front leg (fig. 1). If you hit the deer anywhere within 5 inches $(13 \mathrm{~cm})$ of this point, the bullet will strike a vital organ and the deer will bleed profusely and die quickly. A shot that is within 5 inches above or below this point will strike the heart, aorta (a main blood vessel), or spine. A shot within 5 inches ahead of this point will strike the lungs or the aorta. A shot within 5 inches behind this point will hit both lungs. 


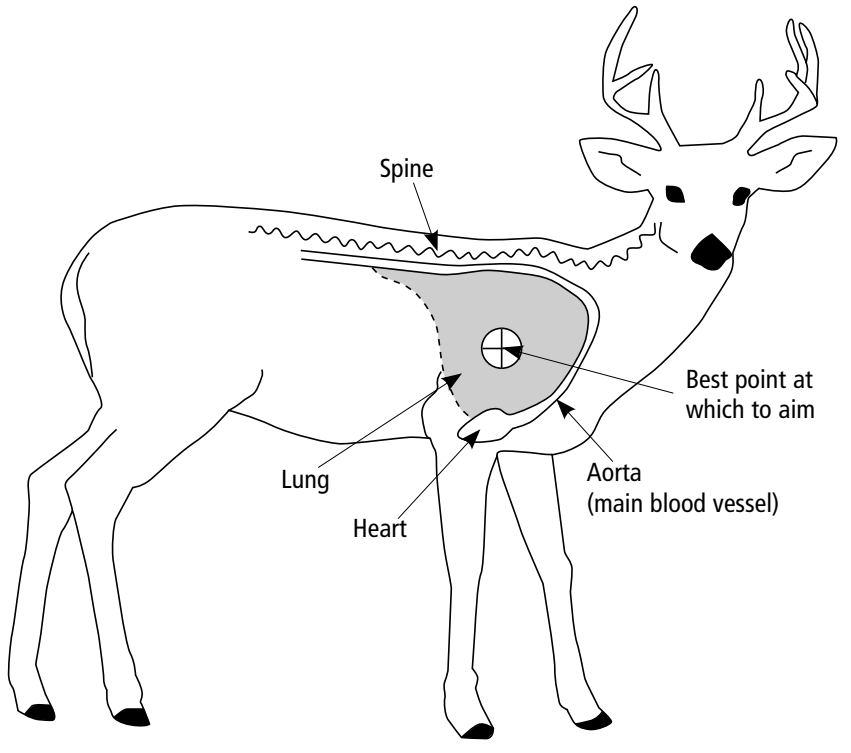

Figure 1. Aim at a point midway between the top of the back and the bottom of the chest slightly behind the front leg.

\section{CHRONIC WASTING \\ DISEASE (continued)}

game handling techniques with 3-D animation, making it a valuable reference for hunters. Produced in cooperation with American Outdoor Productions, this video presents important facts about CWD; provides detailed instructions on field dressing, boning, and butchering a big game animal so as to avoid or remove CWD "hot spots" such as the brain, spine, and lymph nodes; and gives advice on compliance with state carcass transportation regulations.

"Shedding Light on Chronic Wasting Disease" is available in DVD format at a retail price of $\$ 9.95$ plus $\$ 2.00$ shipping/handling (VHS not available). A portion of the proceeds go to the CWD Alliance, which seeks to promote accurate communication about CWD while also supporting strategies that control CWD to minimize its impact on wild, free-ranging deer and elk populations.

While CWD has not been found in deer in California, care in handling is prudent.

(continued)

\section{Equipment} hunting season.
As soon as you have shot at a deer, go immediately to where it fell or was standing. This improves your chance of finding the deer or finding evidence that you hit it (hair, blood, or tissue), and it gives you a chance to trail the deer while the evidence is still fresh and visible. Do not wait for the deer to "settle down" after you have shot it. A wounded deer being trailed by a hunter will bleed more profusely, leave more evidence to trail, and die more quickly than a deer that is allowed to settle down, develop a blood clot in the wound, and recover from the shock of being wounded.

Once you have found the deer you shot, approach the animal carefully and be ready to shoot again if necessary. Look for signs of life, especially eye movement. If there are no signs of life, touch the eye with the tip of the gun muzzle, arrow, or a long stick. If there is any eye response, the animal is still alive and should be shot again through the heart. The heart is located immediately behind the joint of the front leg and the chest, close to the rib cage (see fig. 1). Do not attempt to bleed a wounded deer. Inserting a knife into a live deer can be dangerous and will accomplish little more than requiring you to shoot the deer a second time as recommended. If the deer is dead, there is no point in inserting a knife into the deer because once the heart has stopped pumping, severing additional arteries and veins causes little additional blood loss. Once the deer is dead, correctly mark the appropriate deer tag and attach it to the deer as required by law.

\section{FIELD DRESSING}

It is important to clean and cool the venison as quickly as possible.

- Rubber or latex gloves.

- A length of rope 10 to 15 feet (3 to $4.5 \mathrm{~m}$ ) long.

- A knife with a blade no wider than 1 inch $(2.5 \mathrm{~cm})$ and at least 4 inches $(10 \mathrm{~cm})$ long. Do not use household knives as a precaution against CWD, as cleaning even with bleach does not ensure safety from prions.

- Roll of brown paper towels. Do not use white paper towels due to the potential danger of showing anything white in the woods during deer-

- Two plastic bags if you wish to save the heart and liver.

- Additional bags or a bucket for meat cuts. You may want to prelabel the bags as "tenderloin and ribs," "roasts," "ground beef/stew," etc.

- Cloth and salt for wiping carcass.

\section{THE INSIDE OF A DEER}

Figure 2 shows a buck lying on its back in position for gutting, as viewed from the side. The illustration has been drawn to show the location of principal internal organs and some skeletal features. The organs to be removed in gutting fill the 


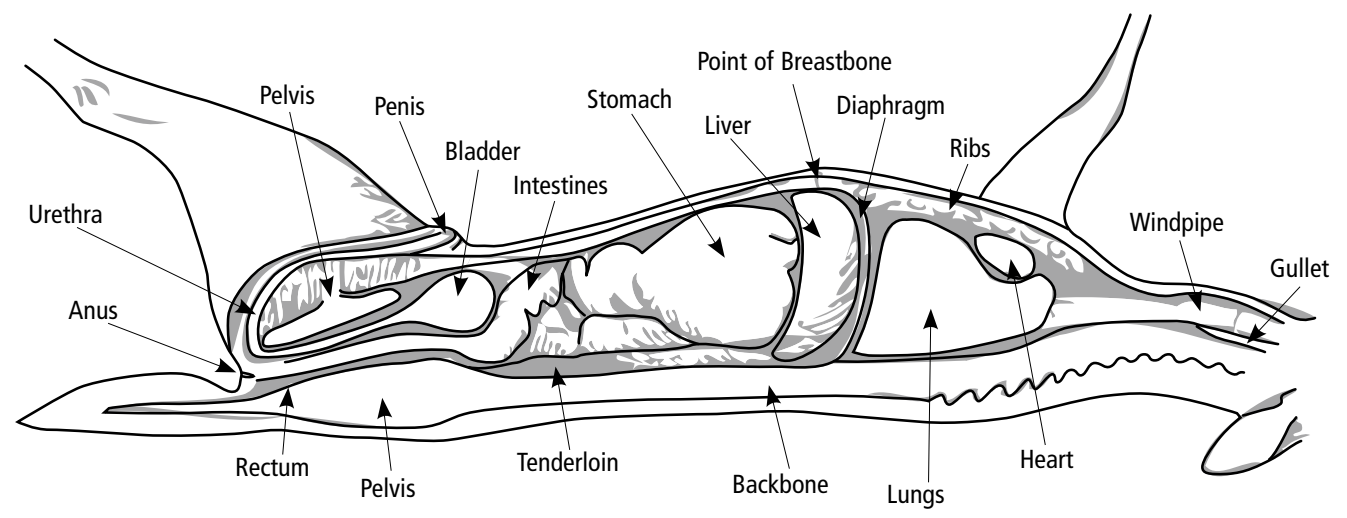

Figure 2. Cross-section of a deer showing the internal organs.

\section{CHRONIC WASTING}

DISEASE, (continued)

\section{General Precautions}

- Do not eat the eyes, brain, spinal cord, spleen, tonsils, or lymph nodes of any deer.

- Do not eat any meat from a deer that appears to be sick before being shot.

- If your deer is sampled for CWD testing, wait for the test results before eating the meat.

- Do not eat meat from a deer found dead by the side of the road.

To further prevent the spread of CWD, the state of California has banned importation of hunter-harvested deer or elk carcasses. Hunters may bring in meat, skin, and antlers, but they may not bring in heads with antlers unless they are taxidermy-finished. The regulations read as follows (current as of 5/5/06):

California Code of Regulations CCR Title 14, Subdivision 3, Chapter 3

§712. Restriction of Importation of HunterHarvested Deer and Elk Carcasses

No hunter harvested deer or elk (cervid) carcass or parts

(continued) entire interior of the body. The lungs and heart are in the chest cavity, formed by the encircling rib cage. Behind them, and separated from the chest by a sheetlike muscle called the diaphragm, lies the abdominal cavity, which contains the liver, stomach, intestines, and bladder. At the rear, these organs are supported by the pelvic girdle.

There is a tunnel-like hole through the pelvis through which the rectum and urethra pass to the outside, where they terminate in the anus and penis, respectively. At the head of the deer, the windpipe and esophagus, or gullet, descend through the neck. The windpipe joins the lungs in the chest; the gullet passes through the diaphragm to join the rumen. Familiarize yourself with the illustration in figure 2. This illustration, along with basic directions, is reproduced in the "In-the-Field Reference Sheet" at the end of this publication for you to print out and take with you into the field if needed.

\section{FIELD DRESSING A DEER}

\section{Before You Start}

- Move the carcass to a spot with plenty of working room.

- Turn it on its back, either level or with the head slightly uphill.

- If the ground is steep, secure the carcass by propping it up with rocks or tying it to a tree.

- If possible, remove your coat and place it in plain sight with your rifle, but be sure you're still wearing safety colors.

- Take off your wristwatch, roll up your sleeves, and put your plastic bag and rope within reach.

- Put on rubber or latex gloves.

- If poison oak is abundant, avoid touching the deer hide with your bare skin.

\section{Basic Method}

This method removes the innards, or viscera, through a slit in the belly between the pelvis and the breastbone. This small opening keeps out most of the leaves, twigs, and other debris admitted by more extensive incisions. The pelvis is not split, preventing exposure of first-rate meat to dirt and drying.

1. Optional: Some hunters first remove the musk glands on the inside of each hock (the rear leg close to where it emerges from the body), peeling off the rough hair and hide where they are located. Removing these glands 


\section{CHRONIC WASTING}

DISEASE, (continued)

of cervid carcass shall be imported into the State, except for the following body parts:

(a) boned-out meat and commercially processed cuts of meat

(b) portions of meat with no part of the spinal column or head attached

(c) hides with no heads attached

(d) clean skull plates (no meat or tissue attached) with antlers attached.

(e) antlers with no meat or tissue attached

(f) finished taxidermy heads

(g) upper canine teeth (buglers, whistlers, ivories).

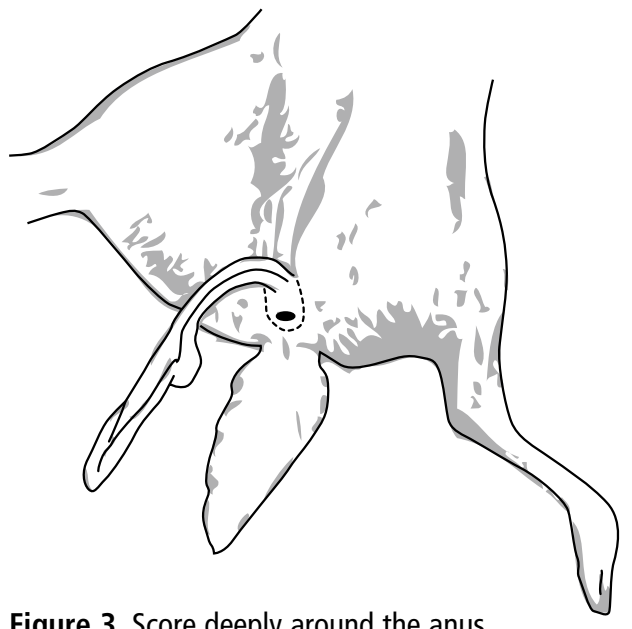
and urethra to free them from the pelvis.

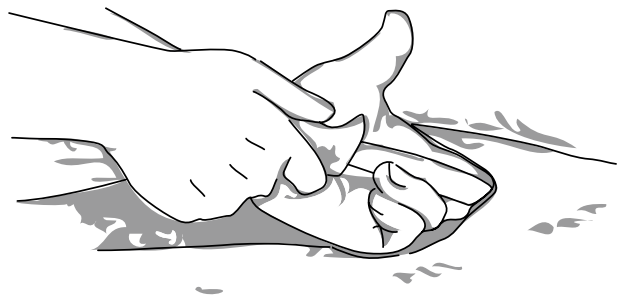

Figure 4. Lift the abdominal wall away from the viscera using a finger on each side of the knife blade. does not improve the flavor of the meat, but if you do it, wipe your hands and knife free of any contamination. Otherwise, leave the glands alone; be careful to avoid touching them and transferring musk to the meat.

2. Begin gutting by lifting the penis with one hand and cutting it and the scrotum free with the other, down to where the penis emerges from the pelvis. Be careful not to cut off the penis. Extend the knife cut to encircle the anus (fig. 3), cutting deeply around both tubes to partly free them from their channel through the pelvis. Lay the penis on the ground pointing downhill and away from the carcass; you will empty the bladder through it later.

3. Insert the knife point (fig. 4), cutting edge up, under the hide only, just ahead of the pelvis where the penis cut was begun, and carefully split the hide to the point of the breastbone (you can feel it where the rib cage starts). The hide will draw back as it is cut, exposing the sheet of muscle beneath and at the same time removing the hair from the proximity of the next cut. This makes skinning easier later. Carefully cut a short slit through the exposed layer of muscle, taking care not to puncture the bladder or intestines underneath. Lift the sheet of muscle away from the intestines by inserting two fingers of the free hand into the slit (see fig. 4). Insert the knife blade between these fingers, edge up, and extend the cut to the breastbone.

4. Notice the liver at the front end of the cut. In front of it is the sheet-like diaphragm closing off the chest cavity. Carefully cut the diaphragm free from the rib cage until you can get both arms up into the deer's chest. Reaching as far into the neck as you can, grasp the gullet (a smooth tube) and the windpipe (it feels like a hose with circular rings) and pull them back. While doing so, ease the knife up into the base of the neck with the other hand, being extremely careful not to cut your hand in the cramped space, and sever both tubes. Pull both tubes back, bringing the lungs and heart with them (you may find the lungs collapsed and surprisingly small).

5. Finish cutting the diaphragm free. With a little snipping of membranes here and there, you can now withdraw most of the deer's viscera, except the bladder and lower intestine, which are still partly attached to the pelvis. Be careful not to damage the tenderloins that lie against the underside of the backbone in the abdominal cavity (see fig. 2). Minimize contact with the lymph nodes (lumps of tissue next to organs or in fat and membranes) as you work. Pile the organs away from the carcass.

6. Squeeze all the urine out of the bladder to avoid a spill and push any droppings out of the last 5 or 6 inches $(13$ to $15 \mathrm{~cm})$ of the rectum. Working from inside, snip off the remaining attachments and pull the penis and anus forward through the pelvic arch. Put them with the rest of the organs on the gut pile. The gutting is now complete.

7. Drain out the body cavity by raising the deer's shoulders and letting the accumulated blood run out through the pelvic opening.

8. Wipe the blood from your hands with paper towels. Use additional paper towels to wipe all the blood from the body cavity of the deer. Be as thorough as possible, keeping in mind that bacteria grow well in blood and can cause meat to spoil and possibly become unsafe. Do not use leaves or a soiled cloth to 


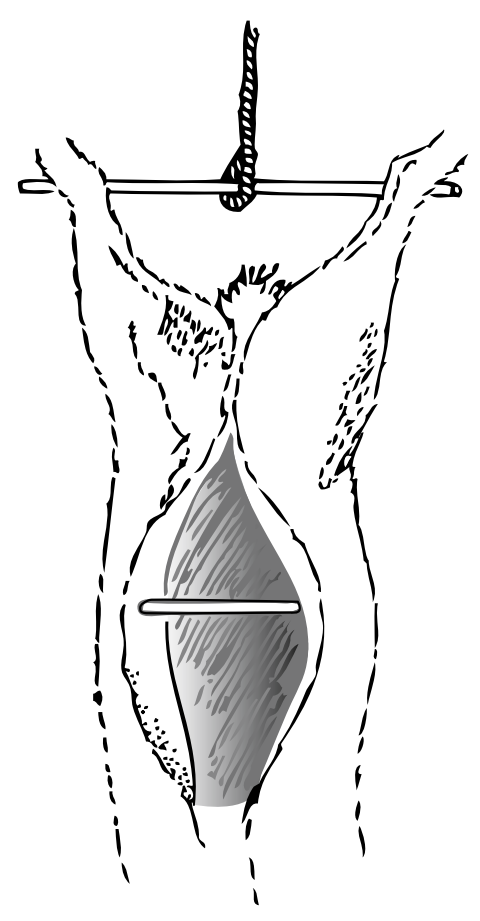

Figure 5. Hanging a deer by its hind legs, as shown, makes butchering easier. clean the blood from the body cavity as leaves and rags are loaded with bacteria that cause spoilage.

9. Separate the heart and liver from the other organs. Drain any excess blood from them, wipe with a clean paper towel, and put them in a plastic bag.

10. Bury the paper towels or place them in plastic bags to be carried out and disposed of later.

11. Optional: Cut out the prime meat cuts and place them in plastic bags at this time. See the section "Skinning and Cutting the Deer Carcass," below. You can leave the bones and hide for scavengers; check your license for local regulations. Alternatively, release the carcass from whatever you used to secure it during dressing and prepare to move it to your home, campsite, or vehicle.

\section{Saving the Hide or Head}

If you are field dressing the deer within the state of California, you may keep the hide and the head. If you must transport the deer into California, refer to the California Code of Regulations in the sidebar above to determine what parts you may bring into the state. If you do not want the hide, bone out the meat in the field and place it in plastic bags. Leave the hide and bones in the field for scavengers (check your license for local regulations).

\section{HANDLING THE DEER CARCASS}

As soon as you get the deer carcass to your campsite or home, hang the carcass to allow the meat to cool quickly and completely. If you did not thoroughly clean the inside of the body cavity when you field dressed the deer, do so as soon as you get the carcass hung. Soak a clean cloth in a saltwater solution ( $1 / 2$ cup salt in 1 gallon water, or 250 cubic centimeters in 1 liter of water), wring the cloth dry, and wipe the inside of the cavity of the carcass with this damp cloth. If the inside of the body cavity has been contaminated by the contents of the bladder, bowel, intestines, or stomach, or with unclean water, mud, or dirt, trim away the surface meat with a knife. Although you may not see contamination, it is still present and must be trimmed. Rinsing is not as effective as trimming away the meat.

A deer carcass can be hung from the antlers, the neck, or the hind legs. Research has shown that it makes no difference in venison quality whether you hang the carcass by its hind legs or its head. If you wish to have the deer head mounted, however, hanging it by its hind legs avoids rope damage to the hide on the neck, head, and ears. It is also much easier to butcher the deer and save the head and cape for mounting if you hang it by the hind legs.

To hang a deer carcass by the hind legs, slice the hide between the leg bone and the large tendon on the back of each leg and insert a sturdy branch, board, wooden dowel, or metal rod as a crossbar through these openings (fig. 5). If you wish, notch the branch, board, or dowel, or bend the ends of the metal rod up to ensure that the carcass does not slip off. Attach a rope to the middle of the crossbar to hoist the carcass.

The major reasons for hanging a deer carcass are to allow the meat to cool and to make the subsequent butchering process easier. Hanging, if done properly, may also help tenderize the meat. Because the majority of deer are less than $2^{1 / 2}$ years old when killed by hunters, there is no need to allow a carcass to hang for more than 1 day. If, however, you have your deer aged by a biologist who informs you that it is $2 \frac{1}{2} 2$ years old or older, you may wish to allow the carcass to hang for more than 1 day. 
If desired, age the meat by holding it at $32^{\circ}$ to $38^{\circ} \mathrm{F}\left(0^{\circ}\right.$ to $\left.3.3^{\circ} \mathrm{C}\right)$ for as long as 10 days to allow natural enzymes to tenderize the meat. As the temperature increases, the aging process occurs faster. Any temperature above $40^{\circ} \mathrm{F}\left(4.4^{\circ} \mathrm{C}\right)$ not only ages the meat faster, but, because of the potential presence of pathogens, may lead to spoilage. Therefore, aging the carcass above $40^{\circ} \mathrm{F}\left(4.4^{\circ} \mathrm{C}\right)$ is not recommended.

If you hang the carcass for 1 to 3 days, or if it is not possible to process it for several days after the deer is killed, then it is vitally important that the carcass be hung properly. If a carcass is to hang for more than 1 day, clean the body cavity thoroughly with a saltwater solution as previously described, and maintain the meat at a temperature below $40^{\circ} \mathrm{F}\left(4.4^{\circ} \mathrm{C}\right)$, preferably from $35^{\circ}$ to $37^{\circ} \mathrm{F}\left(1.7^{\circ}\right.$ to $\left.2.8^{\circ} \mathrm{C}\right)$. If the temperature of the meat exceeds $40^{\circ} \mathrm{F}$, it should be taken immediately to a commercial meat cooler or be processed and frozen.

The carcass may be hung with the hide on or the hide off. With the hide off, the meat tends to dry out and discolor. This makes cooking more difficult, and the outer edge of the meat develops a dry, hard crust that must be trimmed before freezing or cooking. Leaving the hide on protects the meat, but it also makes skinning more difficult. One good reason for skinning and processing your deer as soon as the meat is chilled is that it is easier to skin and process it sooner rather than later.

If the inside of the body cavity is contaminated with stomach or bowel contents and the deer is allowed to hang for several days, the venison will have a gamy flavor and begin to spoil.

Hanging the carcass for more than 1 day during which the meat temperature exceeds $40^{\circ} \mathrm{F}\left(4.4^{\circ} \mathrm{C}\right)$ also causes an objectionable gamy flavor or spoilage, even if the carcass is thoroughly cleaned.

Clean knives with detergent and disinfect them with a solution of 1 teaspoon household chlorine bleach in 1 quart of water ( $5 \mathrm{ml}$ bleach in 1 liter of water).

\section{SKINNING AND CUTTING THE DEER CARCASS}

- Minimize handling of brain or spinal tissues. If removing antlers, use a saw designated for that purpose only, and dispose of the blade in a landfill or by other means legal in your area.

- Dispose of hide, brain and spinal cord, eyes, spleen, tonsils, bones, and head in a landfill or by other means available in your area. Check your hunting license for regulations.

- Do not cut through the spinal column except to remove the head. Use a particular knife for spinal cord or brain cutting only. To guard against CWD, do not use this knife for any other purpose.

- Bone out the meat from the deer and remove all fat (where the gamy flavor resides) and connective tissue (the weblike membranes attached to the meat). Removing the connective tissue also removes the lymph nodes.

- If the deer came from a CWD management or eradication zone, keep meat and trimmings for the deer separate from meat from deer outside the zone. Consult your hunting license to determine the CWD status of the area.

\section{Skinning}

Skinning the deer as soon as possible facilitates carcass cooling. Cut off the front and back legs at the knee joint and peel the skin back before hanging. Removing the bottom part of the leg makes skinning easier and keeps hair off the carcass. If you have hung the deer by the hind legs, begin the skinning process by inserting your knife under the hide (as shown in fig. 4) on the inside of the middle of the hind leg and 
cut upward toward the end of the leg. When you reach the point on the leg where the leg is suspended from the crossbar, cut the hide around the leg, being careful not to cut the large tendon that is holding the carcass up. Grasp a loose edge of the hide and pull downward, pulling the hide free from the hind leg.

As you pull the hide down toward the tail, cut the tail off by placing the blade of the knife at the base of the underside of the tail and slicing into the cartilage connecting the tailbone to the backbone.

Once the tail is cut free, grasp the hide on the hair side and pull outward and downward, pushing on the skin side of the hide with the opposite hand if necessary to assist in separating the hide from the carcass. As you pull the hide down, you will notice a thin membrane of fat. This membrane should stay attached to the meat. If the fat begins to pull off with the hide, carefully cut between the hide and fat to keep it attached to the carcass.

Continue this process all the way down to the front legs, then cut toward the front leg and then down the middle of each leg. Pull the hide free from each leg. If you are not going to mount the deer head, cut the hide from the top of the chest to the chin, if you have not already done so when you field dressed the deer. Continue pulling the hide from the deer all the way down to the base of the skull.

If you are going to mount the deer head, cut the hide on the chest to the front legs, then cut toward the back of the front leg and down the back of the front legs. Pull the hide free from each leg and carefully continue to pull all of the hide free down to the base of the neck. Cut the neck off from the chest and take the hide, neck, and head to a taxidermist.

If you are not going to mount the head, you may wish to remove the head and hide from the carcass at this point. Do so by pulling the hide completely free from where the neck joins the head. Rotate the head as much as possible to help you identify this joint. Once you have done so, insert the knife into the joint and cut from side to side to sever the head and hide from the carcass.

If you have hung the deer by the head and wish to mount the head, it is very difficult to skin the deer and remove the shoulder and neck meat. If you have hung the deer by the head and do not want to mount the head, cut the hide around the neck and down the throat to the chest if you have not already done so. Pull downward on the hide to the shoulders, and follow the skinning procedure described above, but in the reverse order. Do not cut off the head.

Once the hide is removed, inspect the carcass and remove as much hair as possible and any foreign matter. One quick way to remove hair is to singe it with a propane torch.

\section{Cutting the Deer Carcass}

Figure 6 shows cuts of venison you can make from a deer carcass.

\section{Remove the loin from the carcass}

To remove the loin, insert the knife into the carcass along the edge of the backbone and cut alongside the backbone (midline) from the hip to the shoulder, keeping the knife against the edge of the backbone. Cut the loin off at the hip and shoulder and roll these muscles outward away from the spine, using your knife to cut the meat free from the backbone and the rib cage. When both pieces of meat have been cut free from the back, trim off the outer white connective tissue. This tissue, or fell, is the white gristly material that is difficult to grind and chew. It also gives venison a gamy odor and taste. Separate the white connective tissue from the red meat and dispose of the connective tissue.

Cut the loin crosswise into steaks, butterfly steaks, or medallions $1 / 4$ inch $(6 \mathrm{~mm})$ thick for stir-frying. To cut butterfly steaks, cut the loin into pieces approximately 


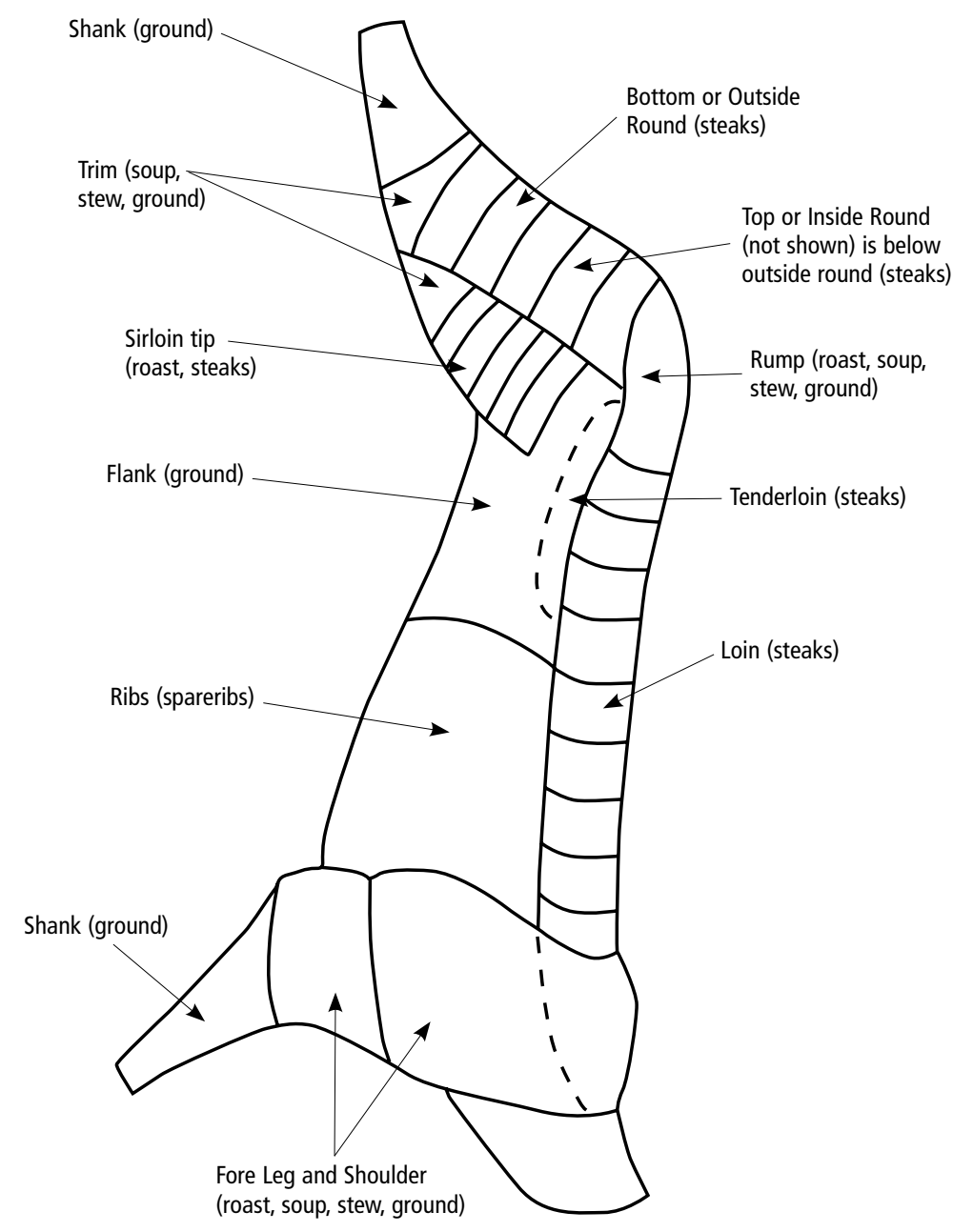

Figure 6. Cuts of venison from a deer carcass.
2 inches $(5 \mathrm{~cm})$ thick, then split each piece from the surface or outside of the muscle to the rib side. Cut the piece almost in half and fold open to make a butterfly. Loin steaks and medallions are always tender and good-tasting. If you want to make chops, saw the backbone in half and cut the meat crosswise into chops. Because this requires a cleaver and/or a saw, cutting chops is not described in detail in this publication. If you saw the backbone, minimize contact with spinal cord.

\section{Cut the shoulder from the carcass}

Hold the front leg away from the rib cage and cut the muscle holding the shoulder to the rib cage all the way up to and including the meat on the backbone. Place the shoulder and leg on a cutting board and cut the meat away from the lower leg (the shank) in any manner you choose. Trim all the white connective tissue off the meat you remove from the shank and set the meat aside to be ground for use in hamburgers, sausage, etc. later or cut up into smaller pieces for stew meat or soup meat. If you plan to grind all of the shoulder meat or cut it into small pieces for stew and soup meat, cut the meat of the shoulder free from the front of the foreleg and shoulder.

Once the meat is free from the bone, remove all connective tissue and set the meat aside to be cut up into smaller pieces or ground. If you wish to make a shoulder roast, start by laying the shoulder down on the cutting board with the outside of the shoulder facing upward. The outside of the shoulder blade has a bony ridge in the middle.

To debone the meat, cut down both sides of the bony ridge on the top of the shoulder blade and, keeping the edge of the knife against the shoulder blade, cut outward, separating the bone from the meat. Carefully separate the meat from the edges of the shoulder blade. Cut the meat on the underside of the shoulder blade away from the bone of the shoulder blade, keeping the knife edge against the bone.

Continue removing the meat down along the foreleg of the deer, being careful not to cut the meat of the shoulder blade that joins the meat of the foreleg. Once the bone has been removed from the meat of the foreleg, the meat of the foreleg can be folded up into the meat of the shoulder and then rolled and tied with string into a roast.

\section{Neck meat}

In most cases, the neck meat is best consumed as ground meat, so cut the meat from the neck bones any way you choose. If you wish to make a neck roast, cut the meat all the way around the neck at the head and the chest. Cut the neck open from head to chest on the bottom of the neck and cut around the neck bones, keeping the neck meat in one piece. Go all the way around the neck, cutting around its bony projections, to remove the neck meat from the bones in one piece. Remove as much of the white connective tissue as possible, roll the meat on itself, and tie with string for a roast. A neck roast from a large, old deer may not be tender. 


\section{Flank meat}

Cut the flank meat away from the sides of the deer. You may choose to discard flank meat, or you can separate the meat from the layers of fat and connective tissue and set it aside to be ground.

\section{Ribs}

Use a heavy knife or a saw to cut the ribs from the backbone. You may separate the rib cage into rib steaks or a roast and spareribs.

\section{Hindquarters}

To separate the hindquarters (the round) from the remaining carcass (fig. 7), locate the hipbone on the back of the deer, insert your knife into the meat along the edge of the hipbone, and cut all along the hipbone, keeping the edge of the knife against the bone of the hip. Next, find the hipbone on the inside of the hip, insert the knife along the edge of the hipbone, and cut along the hipbone, keeping the edge of the knife against the bone. As you separate the meat from the bone, the ball and socket joint of the hip will become visible. Insert the knife into the socket joint and sever the ligaments connecting the ball to the socket. This separates the leg from the hip. Some additional cutting of meat may be necessary to completely separate the leg. Lay the leg down on the cutting board and cut the meat of the lower hind leg (the shank) away from the bone. Handle this shank meat exactly the same as for the lower foreleg (the front shank).

Part of the meat on the upper hind leg extends beyond the end of the bone (the ball). This is the rump (see fig. 7). Cut it off just below the ball. It makes an excellent roast or can be cut into cubes for soup, stew, or grilling.

The meat on the upper hind leg (the round) is divided into three main muscles (see fig. 7). The muscle on the top or front of the bone is almost round, and the two muscles on the side are almost rectangular. Locate a seam between two of the muscles and separate them by cutting the connective tissue that holds them together. Do not slice through the meat. When you have cut the connective tissue in the seam down to the bone, cut all of this meat away from the bone, keeping the edge of the knife against the bone. Remove the bone and then separate the three muscle groups from one another by cutting the connective tissue along the seams.

Start with the half-round piece (the sirloin tip) that came from the top or front of the leg bone. Trim the tips from both ends of this piece of meat. These tips can be used for cubes, stew meat, or soup meat, or they can be ground. The remaining piece of meat can be tied with string into a roast or can be cut crosswise into l-inch steaks. These steaks will be less tender than any other steaks that you can cut from the deer. On a small, young deer, however, these steaks will be tender.

Figure 7. Cuts of venison from the hindquarter of a deer carcass. 
Take the two remaining pieces of meat (the inside and outside rounds) and trim both ends. The trimmings are suitable for cubes, stew or soup meat, or ground meat. The trimmed piece can then be cut crosswise into 1-inch round steaks, which will be almost as tender as the loin steaks. These pieces of meat can also be left whole for roasting, cut into thin medallions for stir-frying, or cut into cubes for venison kabobs. Once again, remove all fat and the white connective tissue from these steaks, preferably before freezing but definitely before cooking.

\section{Inspect the meat cuts}

When all the meat has been removed from the carcass, inspect all pieces of meat again, remove any white connective tissue that you did not remove previously, and remove all foreign matter, especially hair. Cut away and discard any meat that has been bruised by bullet, shot, or arrow. It is better to cut away more meat than necessary than to leave bruised meat, as bruised meat has a strong, gamy flavor. If you think it is necessary, rinse the meat in cold water, but be sure to pat it completely dry with toweling and wash the sink and work area thoroughly with detergent. Sanitize tools and work surfaces with the bleach and water solution described earlier.

\section{Packaging and Freezing the Meat}

Venison can be wrapped in white freezer paper, shiny side in, and taped closed, or it can be placed in a freezer bag with the air removed. Label each package with the cut of meat and the date. Place the meat in a freezer kept at approximately $0^{\circ} \mathrm{F}$ $\left(-17^{\circ} \mathrm{C}\right)$. Spread the meat out over the inside of the freezer as evenly as possible so it freezes solid within 24 hours. Avoid stacking a large amount of fresh meat in one place in the freezer, since the middle layers may take days to freeze solid. After the meat is solidly frozen, you can stack it as you desire.

\section{Grinding}

Venison can be ground at home or placed in the refrigerator and taken as soon as possible to a butcher shop, meat locker, or other business that will grind it for you. Butcher shops may charge a fee for this service. Call ahead to find out when you can deliver the meat and when you can pick it up. Label and freeze the ground meat.

There are many recipes for ground venison, but the following suggestions produce excellent ground meat. If you plan to eat the ground meat as hamburgers, it is best to grind the venison with an additional 5 to 10 percent (by weight) beef fat (suet) or grind it with 30 percent (by weight) lean pork shoulder. The resulting venison burgers will be as good as or better than any beef burgers. If you plan to use the ground venison in dishes such as sloppy joes or chili or with commercial hamburger preparation mixes, you may wish to grind the venison without any additional fat or other meat. Be sure to wash hands, counters, and all equipment with detergent and sanitize with the bleach-water solution described earlier before and after grinding.

Package the ground venison in quantities you find convenient to use, such as $1 / 2$ pound, 1 pound, 2 pounds, and so on. If you package it yourself, wrap it in freezer paper, slick side in, and tape it closed (or use freezer bags) and label with the date and the kind of ground venison. If a business grinds the meat for you, they may be willing to package it as you direct.

Venison that is handled and cooked safely is healthy and flavorful. To be safe, venison should be cooked to at least $154^{\circ} \mathrm{F}\left(68^{\circ} \mathrm{C}\right)$. 


\section{RESOURCES}

For safe handling of meat, see the Partnership for Food Education's Fight BAC! Web site, www.fightbac.org.

For fact sheets including information on safe meat handling, see the USDA Food Safety and Inspection Service Web site, www.fsis.usda.gov.

For a recipe on making jerky, see the National Center for Home Food Preservation Web site, www.uga.edu/nchfp; go to the search page and type "jerky" in the search box.

For questions about meat handling, preparation, and consumption, call the USDA Meat and Poultry hotline at 1-800-535-4555, 10 am to 4 pm Eastern Time.

\section{ACKNOWLEDGMENTS}

The author expresses appreciation to the UC Cooperative Extension Food Safety Workgroup members J. Bruhn, J. Chin, S. Donahue, L. Harris, G. Hall, M. Klenk, C. Lamp, A. Martin, and D. Metz for their technical and editorial suggestions. Thanks to Matthew Livingston, Animal Science Meat Lab Manager, for his technical review. Suggestions are also appreciated from the deer hunters, animal scientists, and veterinarians who reviewed the manuscript. Illustrations by Robin Walton.

To order or obtain printed ANR publications and other products, visit the ANR Communication Services online catalog at http://anrcatalog.ucdavis.edu. You can also place orders by mail, phone, or FAX, or request a printed catalog of our products from:

University of California

Agriculture and Natural Resources

Communication Services

6701 San Pablo Avenue, 2nd Floor

Oakland, California 94608-1239

Telephone: (800) 994-8849 or (510) 642-2431

FAX: (510) 643-5470

E-mail inquiries: danrcs@ucdavis.edu

An electronic version of this publication is available on the ANR Communication Services Web site at http://anrcatalog.ucdavis.edu.

Publication 8204

ISBN-13: 978-1-60107-395-2

ISBN-10: 1-60107-395-X

(C) 2006 by the Regents of the University of California, Division of Agriculture and Natural Resources. All rights reserved.

The University of California prohibits discrimination or harassment of any person on the basis of race, color, national origin, religion, sex, gender identity, pregnancy (including childbirth, and medical conditions related to pregnancy or childbirth), physical or mental disability, medical condition (cancer-related or genetic characteristics), ancestry, marital status, age, sexual orientation, citizenship, or status as a covered veteran (covered veterans are special disabled veterans, recently separated veterans, Vietnam era veterans, or any other veterans who served on active duty during a war or in a campaign or expedition for which a campaign badge has been authorized) in any of its programs or activities. University policy is intended to be consistent with the provisions of applicable State and Federal laws.

Inquiries regarding the University's nondiscrimination policies may be directed to the Affirmative Action/Staff Personnel Services Director, University of California, Agriculture and Natural Resources, 1111 Franklin Street, 6th Floor, Oakland, CA 94607-5201 (510) 987-0096. For a free catalog of other publications, call (800) 994-8849. For help downloading this publication, call (530) 297-4445.

This publication has been anonymously peer reviewed for technical accuracy by University of California scientists and other qualified professionals. This review process was managed by the ANR Associate Editor for Food and Nutrition.

pr-7/06-SB/RW 


\section{Equipment}

- Rubber or latex gloves.

- A length of rope 10 to 15 feet (3 to $4.5 \mathrm{~m}$ ) long.

- A knife with a blade no wider than 1 inch $(2.5 \mathrm{~cm})$ and at least 4 inches $(10 \mathrm{~cm})$ long. Do not use household knives as a precaution against CWD, as cleaning even with bleach does not ensure safety from prions.

- $\quad$ Roll of brown paper towels. Do not use white paper towels due to the potential danger of showing anything white in the woods during deer-hunting season.

- Two plastic bags if you wish to save the heart and liver.

- Additional bags or a bucket for meat cuts. You may want to prelabel the bags as "tenderloin and ribs," "roasts," "ground beef/stew," etc.

- $\quad$ Cloth and salt for wiping carcass.

\section{Before You Start}

- Move the carcass to a spot with plenty of working room.

- Turn it on its back, either level or with the head slightly uphill.

- If the ground is steep, secure the carcass it by propping it up with rocks or tying it to a tree.

- If possible, remove your coat and place it in plain sight with your rifle, but be sure you're still wearing safety colors.

- Take off your wristwatch, roll up your sleeves, and put your plastic bag and rope within reach.

- Put on rubber or latex gloves.

- If poison oak is abundant, avoid touching the deer hide with your bare skin.

\section{Basic Method}

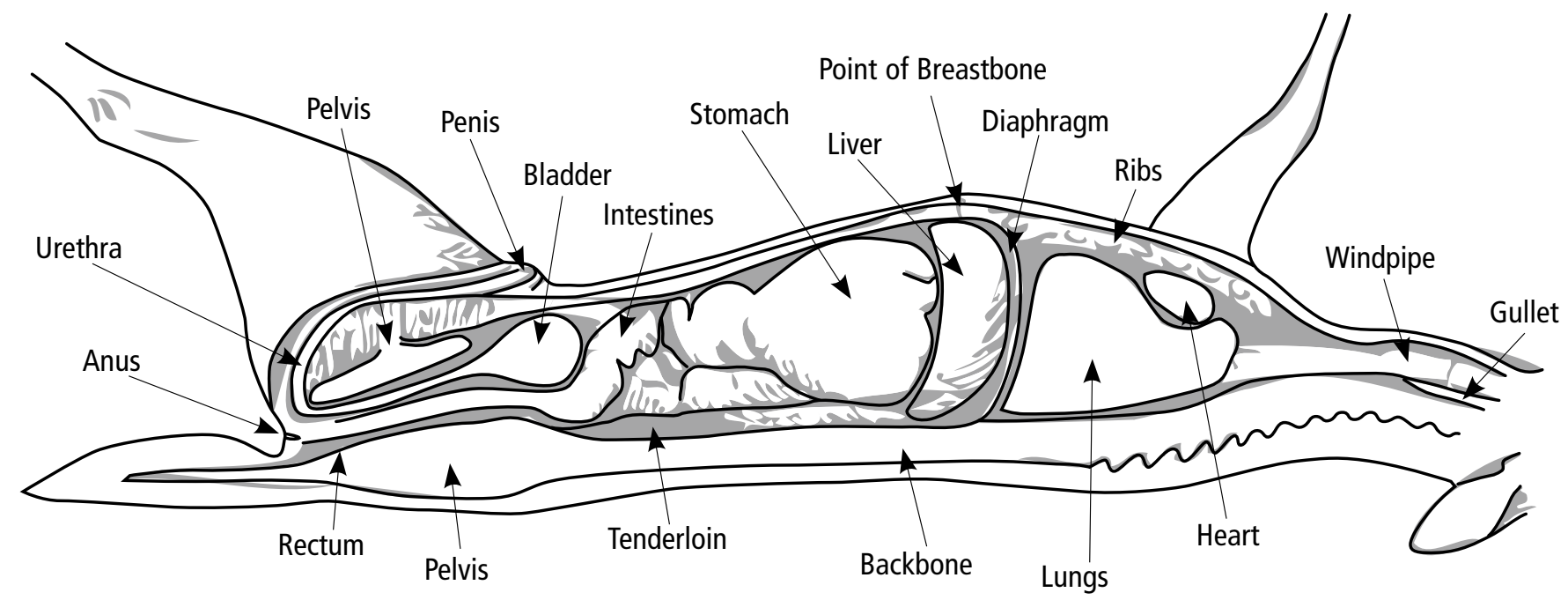

1. Optional: Some hunters first remove the musk glands on the inside of each hock (the rear leg close to where it emerges from the body), peeling off the rough hair and hide where they are located. Removing these glands does not improve the flavor of the meat, but if you do it, wipe your hands and knife free of any contamination.

Otherwise, leave the glands alone; be careful to avoid touching them and transferring musk to the meat.

2. Begin gutting by lifting the penis with one hand and cutting it and the scrotum free with the other, down to where the penis emerges from the pelvis. Be careful not to cut off the penis. Extend the knife cut to encircle the anus, cutting deeply around both tubes to partly free them from their channel through the pelvis. Lay the penis on the ground pointing downhill and away from the carcass; you will empty the bladder through it later.

3. Insert the knife point, cutting edge up, under the hide only, just ahead of the pelvis where the penis cut was begun, and carefully split the hide to the point of the breastbone (you can feel it where the rib cage starts). The hide will draw back as it is cut, exposing the sheet of muscle beneath and at the same time removing the hair from the proximity of the next cut. This makes skinning easier later. Carefully cut a short slit through the exposed layer of muscle, taking care not to puncture the bladder or intestines underneath. Lift the sheet of muscle away from the intestines by inserting two fingers of the free hand into the slit. Insert the knife blade between these fingers, edge up, and extend the cut to the breastbone.

4. Notice the liver at the front end of the cut. In front of it is the sheet-like diaphragm closing off the chest cavity. Carefully cut the diaphragm free from the rib cage until you can get both arms up into the deer's chest. Reaching as far into the neck as you can, 
grasp the gullet (a smooth tube) and the windpipe (it feels like a hose with circular rings) and pull them back. While doing so, ease the knife up into the base of the neck with the other hand, being extremely careful not to cut your hand in the cramped space, and sever both tubes. Pull both tubes back, bringing the lungs and heart with them (you may find the lungs collapsed and surprisingly small).

5. Finish cutting the diaphragm free. With a little snipping of membranes here and there, you can now withdraw most of the deer's viscera, except the bladder and lower intestine, which are still partly attached to the pelvis. Be careful not to damage the tenderloins that lie against the underside of the backbone in the abdominal cavity. Minimize contact with the lymph nodes (lumps of tissue next to organs or in fat and membranes) as you work. Pile the organs away from the carcass.

6. Squeeze all the urine out of the bladder to avoid a spill and push any droppings out of the last 5 or 6 inches $(13$ to $15 \mathrm{~cm}$ ) of the rectum. Working from inside, snip off the remaining attachments and pull the penis and anus forward through the pelvic arch. Put them with the rest of the organs on the gut pile. The gutting is now complete.

7. Drain out the body cavity by raising the deer's shoulders and letting the accumulated blood run out through the pelvic opening.
8. Wipe the blood from your hands with paper towels. Use additional paper towels to wipe all the blood from the body cavity of the deer. Be as thorough as possible, keeping in mind that bacteria grow well in blood and can cause meat to spoil and possibly become unsafe. Do not use leaves or a soiled cloth to clean the blood from the body cavity as leaves and rags are loaded with bacteria that cause spoilage.

9. Separate the heart and liver from the other organs. Drain any excess blood from them, wipe with a clean paper towel, and put them in a plastic bag.

10. Bury the paper towels or place them in plastic bags to be carried out and disposed of later.

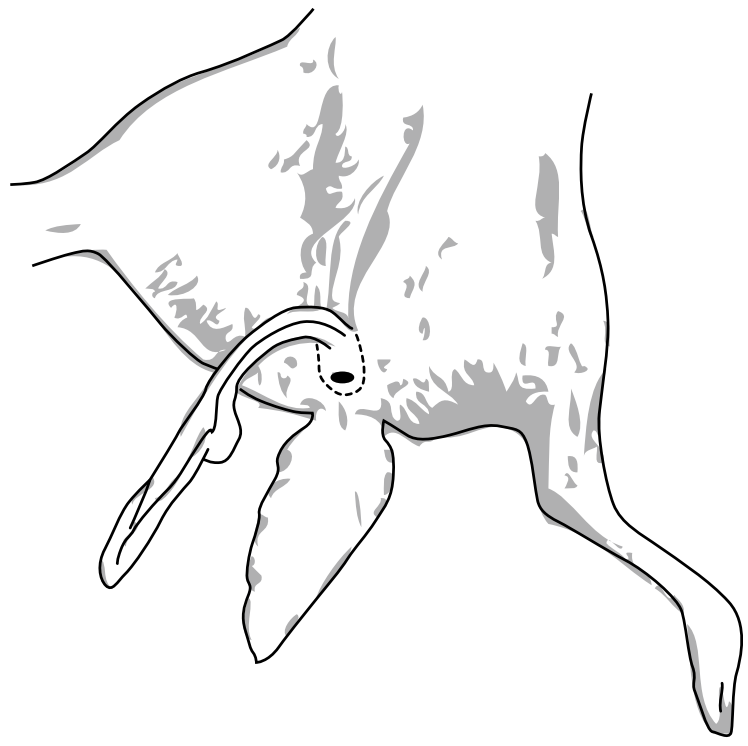

Score deeply around anus and urethra to free them from the pelvis.

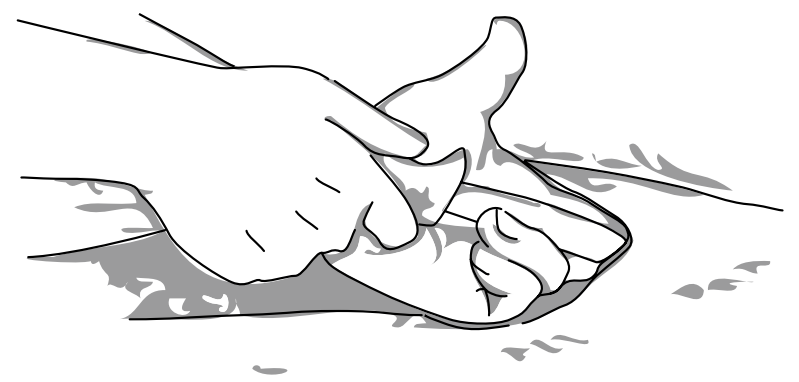

A finger on each side of the blade lifts abdominal wall away from viscera. 